\title{
Pasas y paseros: geometría paisajística en La Axarquía
}

Hay en La Axarquía numerosas pendientes a la solana, situadas entre montes de pizarra a la vera de un casi inapreciable mar que se encara a una sierra imponente. En ellas, luchando por sobrevivir, rectángulos sin arar presididos por triángulos blancos dibujan parte del paisaje de la comarca. Geometría perfecta que parece contradecir la bravura de un paisaje desigual.

Lo que para un visitante son triángulos y rectángulos, para los habitantes de La Axarquía no sólo explican el paisaje sino también un sistema productivo y una cultura, la de las pasas.

Extendidas por el occidente de la comarca, hectáreas de viña intentan, hoy, alimentar a pueblos como El Borge, Almáchar, Cútar o Moclinejo con su producto secado en los omnipresentes toldos o paseros.

Sin pretender alejarnos en el tiempo, hablar de la viña y el paisaje nos remite a la primera de las epidemias que afectarian al paisaje axarqueño en el siglo XIX la filoxera. Esta no solo incidirá en la implantación de productos hasta el momento secundarios como el olivo y el almendro -modificando el propio paisaje-, sino que será determinante para la aparición de devociones y patronos que pretendian paliar las carencias de una tierra devastada. Sin embargo la vid no desaparece en su totalidad y progresivamente volverá a ganar terreno, compartido entonces con el almendro y el olivo, y ya hoy con otros productos sub-tropicales como el aguacate.

A pesar de una historia determinada por la filoxera, emigración, construcción, la elaboración de las pasas continúa siendo un elemento identitario del paisaje y sus diseñadores, los axarqueños, aunque no en el mismo grado en su economía.

Caracterizada por la especie Moscatel, la vid distribuye a lo largo del año sus tareas, antes de poder llevar a cabo la plantá en los toldos.

La primera de las fases es la retirada de los sarmientos que no valen de la cepa durante el mes de octubre. En este proceso, denominado cernillar, se dejan normalmente cuatro brazos a partir de los cuales crecerá el sarmiento de donde debe salir el racimo. Posteriormente, a partir de la Purísima (8 de diciembre) es cuando se enfraga. Esta tarea implica arrancar lo que crece alrededor de la cepa a la vez que se remueve la tierra. Estas labores que se realizan sin la ayuda de ningún animal y son llevadas a cabo por los hombres dejan la vid preparada hasta finales de marzo-principios de abril, periodo en el que se vuelven a trabajar.

Las pendientes y una parcelación lejana a los latifundios de campiña, heredada de una repoblación tardia, dificultan el trabajo con las bestias y presenta una tierra de pequeñas parcelas donde el ser humano continúa teniendo que hacer frente a las tareas agrícolas a lomos de su costal.

La llegada de la primavera, y después de la temporada de la aceituna, da paso al proceso de binar, es decir, el acto de remover la tierra o cavar. Es un proceso más superficial que sirve como sistema natural de sulfatar la tierra. Tal proceso puede durar hasta principios de mayo cuando se esparce azufre por encima de la cepa

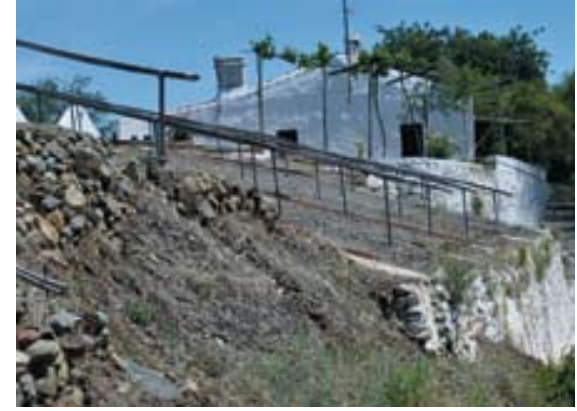

Pasero y lagar en Almáchar. Foto: Marc Ballester Torrents

para evitar que le caiga ceniza (proteger de plagas naturales). Una vez azufrao, se lleva a cabo a partir del 10 de mayo el proceso de espuntar. En dicho proceso se corta la moquilla, punta del sarmiento, dejando dos yemas (una más cercana al brazo y otra por arriba) de donde crecerá el racimo. Este proceso permitirá concentrar el crecimiento de un racimo por sarmiento (dando más calidad a la uva) y proteger el racimo del sol, evitando así que se abra la cepa.

Determinado el crecimiento de la cepa en algunos casos se vuelve a realizar el azufrao (siempre antes de que crezca el racimo porque si no lo quemaría) que lleva a realizar el tapado a partir del mes de junio, que es cuando el racimo ya está creciendo y podría ser dañado por el calor. El tapado puede llevarse a cabo volteando la cepa con algún sarmiento de la misma o cubriéndola con hierbas. Entrado el verano las tareas en la viña se centran en el cuidado y preparación del pasero o toldo.

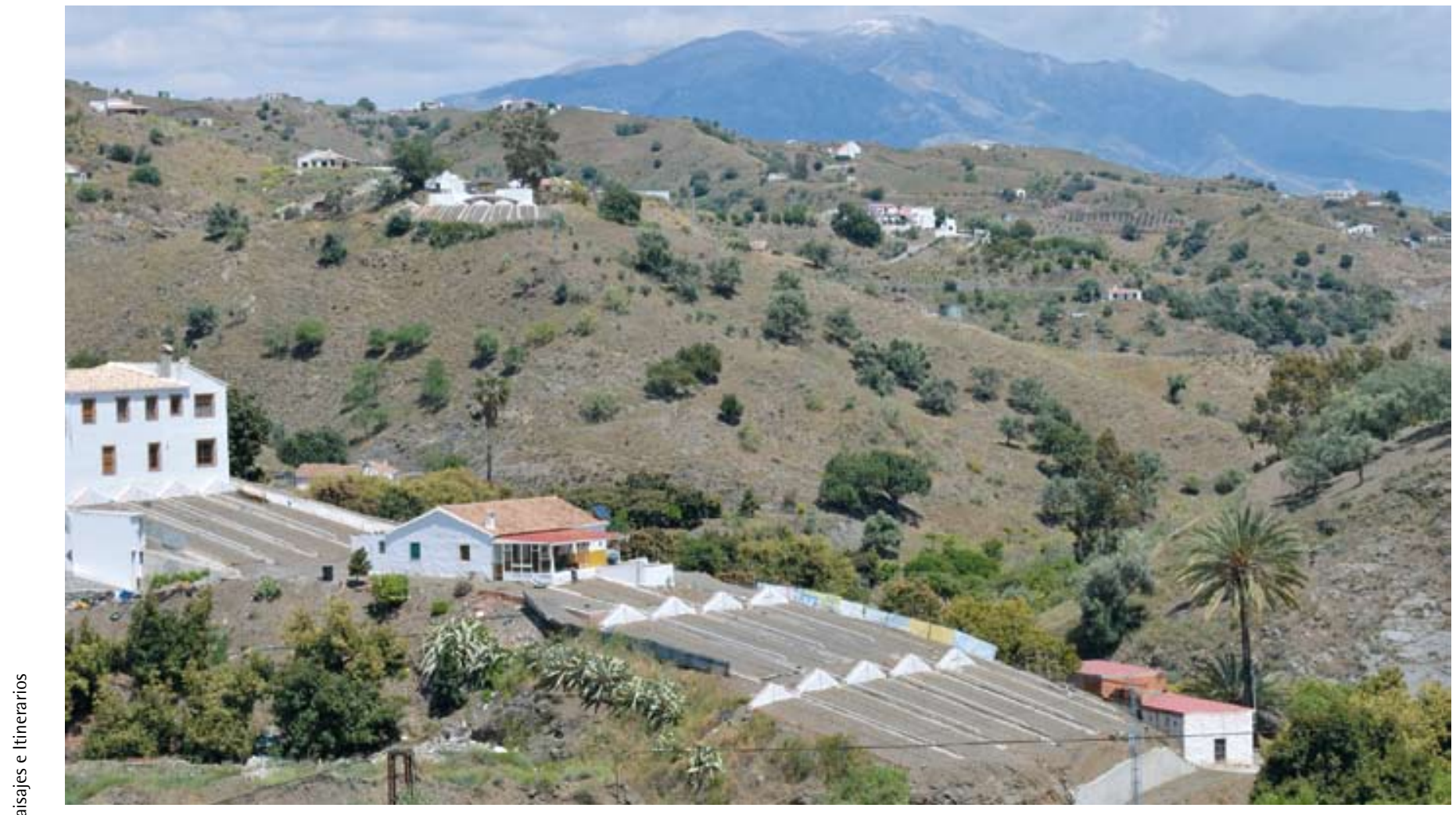

Paisaje pasero en La Axarquía con la Sierra Tejeda-Almijara de fondo. Foto: Marc Ballester Torrents 
A lo largo del año, los paseros son espacios abandonados donde se deja crecer la hierba y se amarran las bestias, así que hay que proceder a limpiarlos y prepararlos para la plantá.

Es a principios de agosto cuando empieza la vendimia. Este trabajo que tradicionalmente implicaba a toda la familia sin distinción de géneros y edades hoy se pone en entredicho debido al cambio en la propia sociedad local. La necesidad de contratación es lo que hace cada vez más difícil de sostener la producción de vid $y_{1}$ en consecuencia, de la pasa. Este cambio progresivo rompe con unas formas que se caracterizaban por el traslado al campo de toda la unidad familiar durante el mes de agosto y principios de septiembre, con la noche de las candelas el 7 y 8 del mismo mes.

Es en este momento cuando empieza el trabajo de la pasa. La elaboración de la pasa de uva moscatel en La Axarquía se caracteriza por el secado de la uva al sol en los paseros o toldos. Una elaboración que se realiza manualmente en sus diferentes fases, plantá, volteo, recogida o levantá, picar y criba.

El pasero o toldo es una porción de tierra rectangular de entre 4 metros de ancho por unos 12 de largo que está presidida por un muro de forma triangular. Del vértice superior del muro salen unas cañas llamadas combrero que avanzan hasta el final del rectángulo dejando el toldo dividido en dos partes iguales llamadas patas. El combrero se apoya en los pinganillos o palos clavados en la tierra hasta llegar al fondo, parte inferior del toldo. En los laterales, a medio metro del límite del pasero, está la calle donde se sitúan unas estacas para agarrar el lienzo que se pone para cubrir de la lluvia. Están ubicadas a un cuarto del suelo para evitar que el agua caiga cerca del pasero y facilitar el paso de las personas.

Los paseros se ubican en las laderas al solano siendo las zonas de umbría las menos propensas a su instalación por ser más húmedas al tocar menos el sol, hecho que alarga el proceso de secado de la pasa.

La plantá recién recogida la uva se hace por racimos poniendo los de más calidad (por el tamaño) en el centro y progresivamente alrededor los que tienen las uvas más pequeñas. El tiempo de cochura (o secado en el pasero), dependiendo del tiempo y de si está en solana o umbria, es de unos veinte dias. El orden coincide con las diferentes clases de pasa. Reviso (mayor tamaño y calidad), reviso medio, aseao, corriente y escombro. Tras el proceso manual de picar -cortar la pasa del racimo dejando el rabillo, ya que si no la pasa se pudre-, se selecciona la pasa en la criba. No hace tantos años que en el proceso de picary cribar mujeres y niños asumian el protagonismo.

Finalmente las pasas se colocan en cajas de madera, las catites o chatos, cajas con capacidad para $10 \mathrm{~kg}$ de pasas en racimo de diferente calidad, o las guarritos, cajas con el dibujo de las propias pasas. Un oficio, un manjar que durante años ha definido cultura y que parece pervivir exclusivamente en un paisaje silencioso a la espera de una nueva epidemia, una epidemia hoy llamada rentabilidad.

\section{Marc Ballester Torrents} Antropólogo

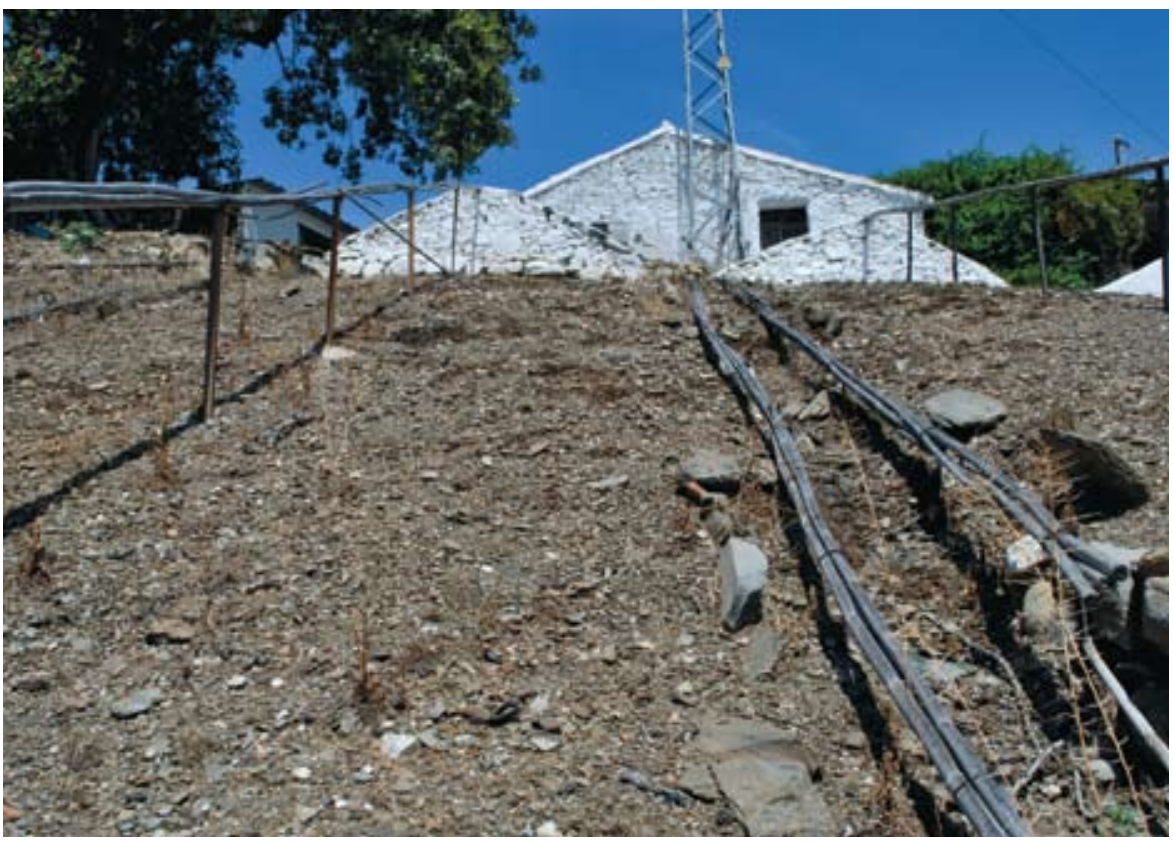

Pasero en Almáchar. Foto: Marc Ballester Torrents

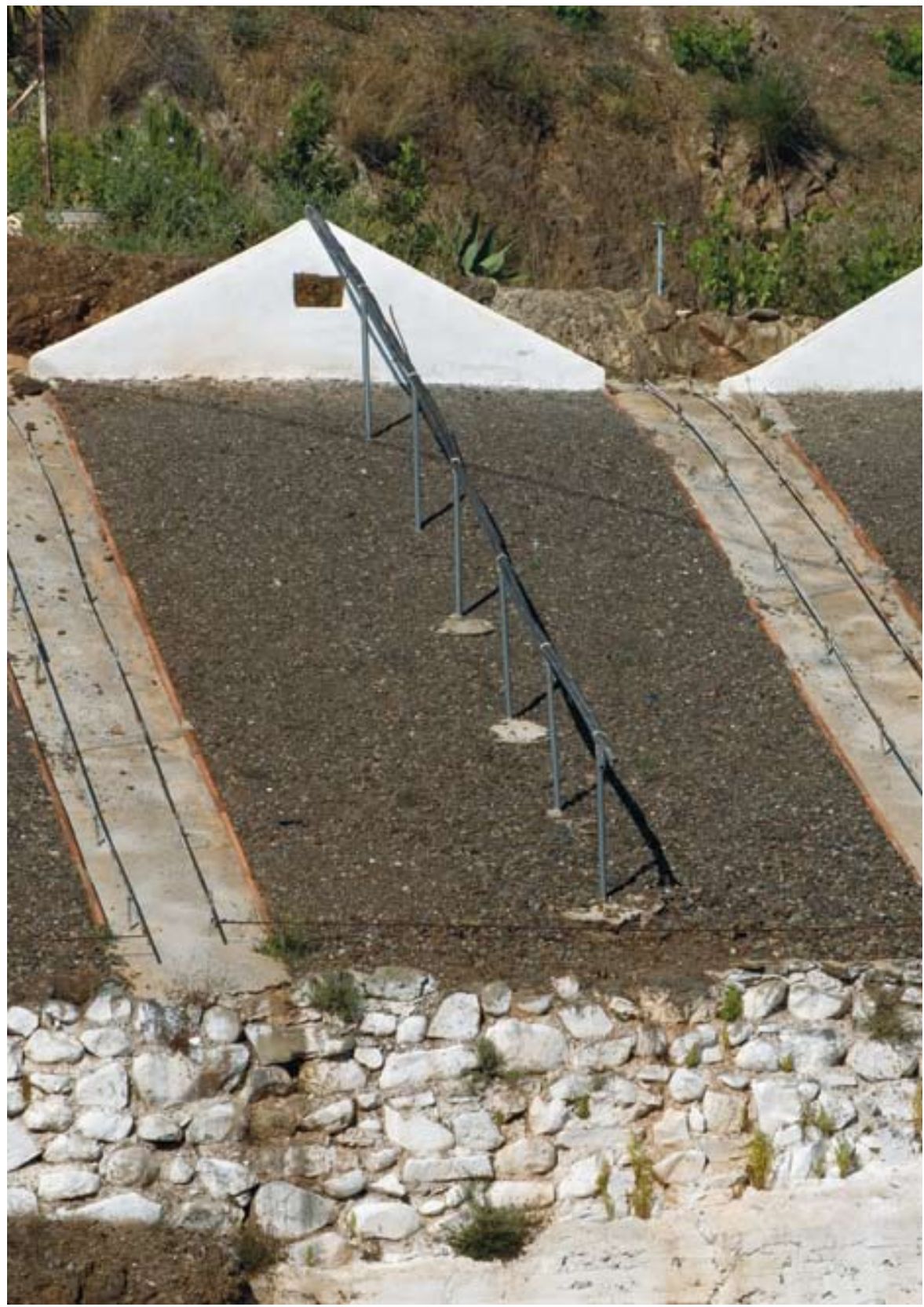

Pasero en Almáchar. Foto: Juan Carlos Cazalla, IAPH 